\title{
Quantitative Empirical Studies on Women's Issues in Islamic Cultures: Introduction to Special Issue
}

\author{
Nuray Sakallı-Uğurlu ${ }^{1}$
}

Published online: 24 October 2016

(C) Springer Science+Business Media New York 2016

\begin{abstract}
The special issue aimed to focus on quantitative research articles covering gender and women's issues in Islamic cultures which have not received sufficient attention. The present issue of gender and women's issues in these cultures adds important information about topics such as the roles of honor, religiosity, and sexism as they interact with gender. In the special issue there are six quantitative research articles focusing on various topics relevant to honor, sexism, economic, and health issues. A study from Turkey examines the associations among benevolent sexism, hostile sexism, religiosity, and the endorsement of honor beliefs in Turkey. Another explores the effects of religious affiliation, patriarchy, and gender on the perception of honor-related crimes in Morocco, Cameroon, and Italy. Views about family issues are explored in a paper from North Cyprus that explores the associations among hostile sexism, benevolent sexism, religiosity, and attitudes toward childlessness. In another paper, researchers from Turkey investigate job-relevant gender issues such as work engagement, job insecurity, and turnover intentions. Finally, women's health in Muslim cultures is the focus of papers on health screening behaviors in Turkey and on factors relevant to menopausal symptoms of women in Pakistan. In the introduction, the main purposes of the special issue articles are introduced. Then, the importance of studying honor, sexism, religiosity, the economic situation of women, and women's health issues in Islamic cultures are covered. Some suggestions for future studies and implication and applications
\end{abstract}

Nuray Sakallı-Uğurlu

nurays@metu.edu.tr

1 Department of Psychology, Middle East Technical University, Ankara, Turkey of the research findings also are discussed. Finally, limitations of the special issue are presented.

Keywords Muslim women · Islam · Quantitative studies . Honor · Sexism · Religiosity · Patriarchy · Muslim Countries . Health $\cdot$ Menopause

Women all over the world experience many social, educational, economic, political, health, and sexual problems. They are exposed to prejudice and discrimination (Glick et al. 2000, in a cross-cultural study including 19 nations: Australia, Belgium, Botswana, Brazil, Chile, Colombia, Cuba, England, Germany, Italy, Japan, the Netherlands, Nigeria, Portugal, Spain, South Africa, South Korea, Turkey, and the United States; Swim et al. 1995 in the USA). The minority position of women has been studied by many researchers from different scientific areas such as sociology (e.g., Richardson and Taylor 1983), anthropology (e.g., Lewin 2005), women and gender studies (e.g., Jaggar and Rothenberg 1993), psychology (e.g., Eagly et al. 2012), political science and public administration (e.g., Guy and Newman 2004), and economics (e.g., Eckel and Grossman 1996). It appears that most of the published empirical studies in psychology came from developed Christian countries. Of course, there are studies about women's disadvantaged position in Islamic cultures (e.g., Hamzah et al. 2016 [Malaysia]; Kulwicki 2002 [Jordan]; Sakallı 2001 [Turkey]) but they are fewer in number.

For example, Sheridan and North (2004) reviewed 1354 abstracts in the PsycINFO database containing the terms Islam, Muslim and/or Muslem. They analyzed the resulting database in terms of article type (e.g., empirical works), publication type (e.g., book), topic (e.g., health, education), place of publication (e.g., United States), and religious background of author (assessed on the basis of the first author's name). 
They found that Islam was the focus of only a small proportion of the total number of published works in psychology. Furthermore, some of the studies on Islamic cultures have been conducted with Muslim participants in Western countries (e.g., Loewenthal et al. 2002 [UK]). Others have been published in their original country with their own language (e.g., İmamoğlu and Yasak 1993 [Turkey]).

However, it is important to focus on women's issues in Islamic cultures to understand the existing situation for women in developing Muslim countries and to disseminate the findings to wide range of readers. The quantitative studies included in the present Special Issue should help readers to identify and to recognize how Muslim women's social, economic, and health lives are influenced by socio-cultural factors such as sexism, honor, and religiosity level in Muslim countries. It is hoped that the publication of this issue may demonstrate associations between mentioned factors and may encourage researchers to further study women's issues in Muslim countries in which gender inequality is very high (Klingorava and Hovlicek 2015; Küçük 2013).

Consistent with the aims and scope of the journal of Sex Roles, the special issue covers original quantitative research articles relevant to women's issues in Islamic cultures where there is a wide gap between men and women (Küçük 2013). Relying on the information in the 2012 Global Gender Gap Index (GGGI), Küçük (2013) argues that the gender gap in economic opportunities and participation, educational attainment, health, and political empowerment is common in almost all of the Islamic world. Similarly, the 2015 GGGI, published by the World Economic Forum (2016), also demonstrates a wide gender gap in economic opportunities and participation, educational attainment, health, and political empowerment in many countries, especially Muslim countries. Looking at the 2015 GGGI ranking for the countries which are included in the articles of the special issue, in terms of global ranking for the degree of gender disparity favoring men, Italy ranks 41th, Cameroon 90th, Cyprus 100th, Turkey 130th, Morocco 139th, and Pakistan 144th among 145 ranked countries. Thus, except for Italy, which is a majority-Christian country, these Muslim countries fall within the worst percentiles of GGGI in 2015. A recent quantitative study comparing three main religions (Christianity, Islam, and Hinduism) (Klingorava and Hovlicek 2015) also demonstrated that the highest levels of gender inequality across literacy, university education, political participation, labour force, and gender inequality index were observed in Islamic culture.

The current issue includes six reserch articles relevant to various variables about women's issues such as honor endorsement, honor-based violence, sexism, religiosity, patriarchy, workforce participation, and health in different Muslim countries such as Turkey, North Cyprus (Turkish part of Cyprus), Morocco, Cameroon, and Pakistan. The researchers in the current issue are from psychology, business administration, and economics departments. In the present article, I aim to introduce the main purposes of the articles included in the special issue and to briefly summarize the implications and applications of these studies.

\section{Research Articles in the Issue}

In this special issue I start with sexism and honor-relevant issues because the two social concepts may be the most important social constructs which may influence various attitudes and behaviors toward women. Although Muslim countries interpret Islamic religion and rules differently and women's status varies in different cultures (Sechzer 2004), researchers have indicated that the level of sexism is high in Islamic countries (Kandiyoti 2011 [Turkey]; Glick et al. 2000 [a cross-cultural study including 19 nations: Australia, Belgium, Botswana, Brazil, Chile, Colombia,Cuba, England, Germany, Italy, Japan, the Netherlands, Nigeria, Portugal, Spain, South Africa, South Korea, Turkey, and the United States]; Taşdemir and Sakall1-Uğurlu 2010 [Turkey]). Earlier studies using samples from Turkey have shown that sexism was associated with prejudice against women who have premarital sex (Sakall-Uğurlu and Glick 2003), attitudes toward sexual harassment (Sakall1-Uğurlu et al. 2010), perception of rape (Sakall1-Uğurlu et al. 2007), and attitudes toward violence against women (Sakallı 2001).

Glick et al. (2016) investigated the question of why men and women favor honor beliefs in Turkey. They examined the associations among benevolent sexism, hostile sexism, religiosity, and endorsement of honor believes in Turkey. Glick et al. (2016) presented data indicating that benevolent sexism - which is accepted as a subjectively favorable, gender-specific, system-justifying ideology — was a predictor of Turkish women's honor beliefs, but not of men's. It also demonstrated that hostile sexism, which is openly antagonistic toward women, was a predictor of Turkish men's honor beliefs. Further, the study reveales that Islamic religiosity positively predicts honor beliefs for both genders. The authors argued that combating benevolent sexism and promoting feminist interpretations of Islamic religiosity may help to empower Turkish women to challenge honor beliefs, some of which are associated with negative attitudes or behaviors toward women such as prejudice against women who have premarital sex (Sakall1-Uğurlu and Glick 2003) and attitudes toward violence against women in Turkey (Ceylan 2016).

In another honor-relevant study conducted by Caffaro et al. (2016), the perception of honor-based violence against women was examined in female and male students from Morocco, Cameroon, and Italy which are considered as honor countries but are different from each other in terms of religion, gender 
roles, and values. The authors indicated that their participants from Morocco are all Muslim, others who are from Cameroon are all Christian, and the rest from Italy are Christians and Atheists. In their study, participants read stories about a woman who was exposed to violence by her father. The participants evaluated the victim's responsibility, the assailant's responsibility, the seriousness of the incident, and punishment variables. The results showed that the perception of honor-related violence was influenced by the participants' nationality and gender. Italians evaluated the incident as a crime more than Moroccans did, and the latter more than the Cameroonians. The same significant differences among groups were observed for the judged seriousness of the incident. Furthermore, Italians attributed significantly less responsibility to the victim and more responsibility to the assailant than did the participants from Morocco and Cameroon. Accordingly, Italians also proposed significantly more severe punishment than Moroccans and Cameroonians did. Cameroonian women attributed more responsibility to the victim and less responsibility to the assailant than their male counterparts did, and Italian women attributed more responsibility to the assailant than their male counterparts did. The researchers indicated that these results were compatible with a context of patriarchal ideology, which is still in force in Cameroon and Morocco.

Similar to two previous studies, Husnu (2016) covers the associations among hostile sexism, benevolent sexism, religiosity, and attitudes toward childlessness in North Cyprus. She suggested that prescriptive norms about parenthood, the value of children, and ideas about child rearing may influence women's attitudes and behavior. Religiosity as well as hostile and benevolent sexism were hypothesized as being relevant to men's and women's attitudes toward childlessness. Her findings demonstrated that in women, higher levels of religiosity predicted negative attitudes toward childlessness, whereas benevolent sexism was marginally predictive of attitudes toward childlessness. The results were a bit different for male participants. For men, benevolent sexism was significantly predictive of negative attitudes toward childlessness whereas higher levels of religiosity were only marginally predictive. Further, benevolent sexism partially mediated the relationship between religiosity and negative attitudes toward childlessness in both women and men. Thus, benevolent sexism had a mediator role between religiosity and attitudes toward childlessness.

Another study further examines job security and work engagement issues in a Muslim country. Metin-Camgoz et al. (2016) test an integrative model that considers differential gender effects for the mediating role of work engagement on the relationship between job insecurity (as general concern about losing one's job and concern about losing privileges) and turnover intentions with private banking employees from
Turkey. The article contributes to the literature by focusing on the ignored role of gender perspective in job insecurity and its organizational outcomes in a predominantly Muslim country. The results indicated that work engagement was a mediator of the association between concern about losing job privileges and turnover intention for both men and women. However, work engagement was not a mediator of the association between turnover intention and the job insecurity involving concerns about losing the job itself for both men and women. These researchers suggested that their study might be helpful in better understanding the female workforce in Muslim cultures. They argued that the business environment should more strongly support gender equality and ensure work engagement.

Naviar Sen et al. (2016) focus on workforce participation and its effect on health-protective behavior in women in the Muslim country, Turkey. The researchers used the Health Belief Model to examine the influence of workforce participation on women's screening behaviors and intentions for clinical breast exam, mammography, and PAP smear. They found that across all screening behaviors, homemakers were less likely than were working and retired women to be up-to-date on their current health screenings. Income, education, and workforce participation were also important variables relating to screening behavior. When income and education level were lower, women screened less, whereas when workforce participation was higher women screened more. Workforce participation was thus helpful for women to have higher intentions to screen. Their results showed that homemakers are in a vulnerable position due to lower rates of cancer screening. Researchers suggested that homemakers should be targeted for interventions. Interventions raising perceptions of susceptibility to cancer and ensuring feelings of efficacy, possibly targeting neighborhoods during working hours, could be useful in increasing screening rates among these women. It seems that economic and educational improvements are needed for women in developing Muslim countries to increase healthprotective behaviors.

Finally, Jamil and Khalid (2016) examined associations among exercise, physical activity, social support, attitudes towards aging/menopause, and menopausal depression in Pakistani women. They administered the Menopausal Symptoms Scale and Social Support Questionnaire to 110 women going through natural perimenopause in Pakistan. Their results demonstrated that that regular exercise and physical activity level negatively predicted menopauserelated symptoms. Further, satisfactory relationships with the husband negatively predicted menopause-related depression. In addition, there was a negative correlation between having a positive attitude towards aging/menopause and menopausal depression. 


\section{Discussion and Suggestions for Future Research}

The aim of the special issue was to gather research on issues relevant to women in Islamic countries to better understand the existing situation for women, to consider some of the problems for women in developing Muslim countries, and to disseminate the findings to a wide range of readers. Consistent with the aims and scope of the journal of Sex Roles, the special issue covers only original quantitative research articles relevant to women's issues in Islamic cultures.

The articles in the special issue reveal some of the diversity of women's issue. Some researchers focus on the issue of women's honor, which is very popular topic in many social scientific disciplines such as sociology (Richardson and Taylor 1983), anthropology (Peristiany 1965 [published in the UK about honor issues in Mediterranean countries]), and psychology (Leung and Cohen 2011 [the USA]; Vandello et al. 2009 [the USA]). Both Glick et al. (2016) and Caffaro et al. (2016) investigated the associations among honor, religiosity, and sexism, showing that these three main social constructs may be relevant to each other. Glick et al. (2016) measured the level of religiosity and of honor endorsement in a Muslim country (Turkey) whereas Caffaro et al. (2016) only asked participants' religious affiliation as Muslim, Christian, and Atheist to explore perception of violence against women in different nations such as Morocco, Cameroon, and Italy. Results of these studies suggest that perception of honor are an important social variable in understanding attitudes toward women in Islamic cultures. Honor which is defined through women's social and sexual behavior (Sakall1-Uğurlu and Akbaş 2013; Sever and Yurdakul 2001) seems to be associated with sexism, religiosity, and violence against women. In fact, a recent experimental study on the association between honor endorsement and acceptability of honor-based violence against women (Ceylan 2016) demonstrated that Turkish participants approved men's violence against his wife when he based his aggression on maintaining family honor.

In addition, from the perspectives of ambivalent sexism and religiosity, Husnu (2016) investigated attitudes toward childless in a Muslim culture. She indicated that studying attitudes toward childlessness and their correlate - such as religiosity, hostile and benevolent sexism — were important for several reasons. First of all, the topic is relevant to women's right to have a child or have control over their bodies. Second, as in other cultures, womanhood in Islamic cultures is equated with motherhood. As cited in Naviar Sen et al. (2016), the World Values Survey Association (2014) found Turkish people believe that a woman has to have children to be fulfilled. If the woman cannot have a child, she may be blamed. Similarly, an unpublished study on stereotypes of men and women in Turkey by Sakall1-Uğurlu and Türkoğlu (2016) showed that when college students were asked to define "woman" (not a girl), the most frequently used adjectives were mother, housewife, dependent (to a husband), nurturing, and responsible for home/children. Thus, these findings suggest that every "real" woman was expected to get married and have at least one child. Further, prescriptive norms about being a woman create high pressure on women who do not want to have a child. They may feel uncomfortable, emotionally troubled, and stressed (Copur and Koropeckyj-Cox 2010). In addition, many cultures highly value parenthood and women are prescribed to many responsibilities in childrearing (SakallUğurlu and Türkoğlu 2016; Sunar 2002 [Turkey]). Finally, women who desire to stay childfree may be judged and negatively evaluated by the society (Copur and Koropeckyj-Cox 2010 [Turkey]; Koropeckyj-Cox and Pendell 2007 [the USA]).

As mentioned earlier, Islamic countries usually rank poorly in economic participation and opportunities for women in the GGGI (World Economic Forum 2016). Many Islamic women have less chance to work outside their home than do other women. When they do find a job, some may feel powerless and their desire to continue their job may decrease because of a threatened job situation. Some may fear losing their job or job privileges. These perceptions of job insecurity may influence their attitudes and behavior toward their job and affect possible opportunities to move to a higher position in their work. Some women may have less positive attitudes about their work and feel less fulfilled (Rosenblatt et al. 1999 [Israel]; Staufenbiel and König 2010 [Germany]). It seems that the variables examined in the study of MetinCamgoz et al. (2016) are very important for many countries to solve the economic participation of and maintenance of women in the workforce. Islamic countries should deal with beliefs about discrimination against women in the workplaces. They should increase job and promotion opportunities for women. Sexist beliefs make it difficult for women to find a job and to move to upper positions in their jobs. Government, politicians, and new social norms should create an environment in which women should be able to feel that they deserve and are entitled to any jobs they want to have in their own countries.

Being employed not only brings advantages to women in terms of earning money, economic independence, and selffulfillment (Moghadam 1998) but also may lead women to take health-protective actions. As Naviar Sen et al. (2016) study indicates, workforce participation may increase women's cancer-screening behaviors. Working women, as compared to homemakers, focus on their health. They appear to more easily take preventive measures for health. In addition to workforce participation, income level and education level may be important variables to influence health-protective behaviors of women. Higher income may increase the access to healthcare facilities. Higher income and education also may increase women's knowledge about the importance of 
protective health behaviors (Skevington 2010 [including samples from 23 countries Argentina, Australia, Brazil, Bulgaria, China, Croatia, Germany, Greece, Hungary, Israel, Italy, India (Madras and New Delhi), Japan, Malaysia, Netherlands, Nigeria, Norway, Romania, Russia, Spain, Turkey, UK, and USA]). In addition, these variables may intersect among women whose income and education are lower. Workforce experience may increase the likelihood of health protective behaviors. Thus, economic participation, education, and participation in life outside the home aids women to have a healthy and happy lifestyle.

Finally, Jamil and Khalid (2016) focus on health issues of women who are going through natural perimenopause in Pakistan. They examined the correlations among attitudes toward menopause, attitudes toward aging, social support, relationship with husband, physical activity, exercise, educational level, and menopausal symptoms. Similar to Naviar Sen et al. (2016) findings, education level was an important variable for women's attitudes toward aging and menopause. Extending other studies in the special issue, Jamil and Khalid found that women's health was related not only to physical activities and exercise but also to having a more satisfying relationship with their husband. Women who were more satisfied with their marital relationship were less prone to menopausal depression.

It seems that education, gender roles, and sexist ideologies are very important variables influencing women's lives. Consequently, it is necessary to develop some intervention programs to educate not only women but also men in order to change sexist beliefs (Flood 2015). However, it may be very difficult to change these sexist beliefs, especially benevolent sexist attitudes, because benevolent sexism functions to prevent changes in sexism (Becker and Wright 2011 [the USA]; Moya et al. 2007 [the USA]). Researcher have suggested that people may not percieve benevolent sexism as prejudice and discriminatory (Barreto and Ellemers 2005 [Dutch sample]; Swim et al. 2005 [the USA]). People may prefer holding benevolently sexist attitudes because it may be associated with positive well-being of women and men (Naiper et al. 2010 [the USA]). As earlier researchers have suggested, combating benevolent sexism may require some new strategies. For example, research that presented how benevolent sexism undermines women's performance (Dardenne et al. 2007 [Belgium]) may be emphasized. Similarly, researchers may focus on the stereotypes of man and manhood issues (Vandello and Bosson 2013 [the USA]) to understand and solve the strongly justified gender-roles system. In that manner, examining the precarious social structure of manhood may highlight why some men are so prone to percieve women's involvement in social and work life as a threat
(Atkinson et al. 2005 [the USA]; Netchaeva et al. 2015 [Italy]). Further, Flood (2015) argues that understandings of men and masculities is beneficial to decrease violence against women. Some social psychological theories such as system justification (Jost and Kay 2005) may also provide some explaination why both genders still support the existing gender system. It is understandable why men want to keep the existing system because they have advantages in many areas such as education, politics, and economy.

A new gender system can be created and introduced to Muslim countries because it is possible to create new norms (Sherif 1935) for both men and women, but the restrictions in religion may not allow the changes. As recently suggested by Klingorava and Hovlicek (2015), higher levels of religiosity in Muslim countries may tend to magnify gender inequality. In the same way, the patriarchal system now seen in Muslim countries may infuence women's lives negatively (Glick and Fiske 1996 [the USA]; Kandiyoti 1988 [Turkey]; Moghadam 1998 [Middle East and North Africa]). It is hoped that some of the data offered in this Special Issue may provide greater understanding about how gender beliefs relate to other aspects of culture such as religiosity level and patriachy.

\section{Limitations of the Special Issue}

Turning to limitations, in terms of methods, the special issue only focuses on quantitative empirical studies in order to provide consistency in the issue. The studies in the present issue are all correlational. In the future, it is hoped that researchers from Muslim countries will publish more studies using different methods such as experimental studies, which can show cause-and-effect relationship between variables, or qualitative studies, which can describe in greater detail the status of women in Muslim countries.

In addition, the articles in the present issue were written by researchers from psychology, business administration, and economics departments. As mentioned earlier, other scientific areas also study women's issues. It may be better to have interdisciplinary studies on women's issues to widen our perspectives on women's issues in the future. It is also interesting that the authors of the articles in the special issue are mainly women. Only Peter Glick from the United States and Lemi Baruh and Tarcan Kumkale from Turkey are male authors. Peter Glick specifically works on ambivalent sexism in the United States (e.g., Glick et al. 2000, whereas others do not generally study sexism or women issues. Lemi Baruh (e.g., Baruh and Cemalcilar 2015) researches communication issues; Tarcan Kumkale (e.g., Kumkale and Albarracín 2004) studies attitudes and persuasion issues in general. It seems that women's issues are mainly studied by women researchers in Muslim countries. This information may raise a question regarding why male researchers, especially 
Muslin men, are not interested in studying women issues in Muslim countries.

Finally, four studies in the special issue include Turkish samples. Husnu's study (Husnu 2016) is from North Cyprus which is Turkish. Both Turkey and North Cyprus are Islamic countries but they are secular. They do not use Muslim law. They are democratic countries so that they are different from some other Islamic countries. In addition, women's status in other Muslim countries may be different from the Turkish population. Women have been modernized within the Kemalist modernization process in Turkey (Arat 1998; Coșar and Onbașı 2008). The other Muslim countries, which are from the Middle East, North Africa, or Asia, may have different cultural values and, as a consequence, their interpretation of Islamic religion and rules may be different (Sechzer 2004).

The reason for the dominance of Turkish studies in the special issue is that there were many submissions from the country. There were also other submissions from Pakistan, Bangladesh, Azerbaijan, and Tunisia but during the review processes they were not accepted. The rejected papers were about empowerment, working environment of women, health problems of women, sport participation of women, and political participation of women. Some of these topics were already covered in the special issue with the accepted manuscripts. Other important topics which are not included in the special issue should be examined in the future. For example, researchers can empirically investigate how women in Islamic culture perceive themselves and how these perceptions differ from those of women from other cultures, what kinds of attitudes they have toward Islam and its rules, how families or parents influence women's decision-making, and the conflict between family and work. Having the final word, the topic of women in Islamic Culture is very wide to cover in one special issue. Researchers should continue to study the problems of women and aim at providing solutions to women's problems in Muslim countries.

\section{References}

Arat, Y. (1998). Feminists, Islamists, and political change in Turkey. Political Psychology, 19(1), 117-131. doi:10.1111/0162-895 X.00095.

Atkinson, M. P., Greenstein, T. N., \& Long, M. M. (2005). For women, breadwinning can be dangerous: Gendered resource theory and wife abuse. Journal of Marriage and Family, 67, 1137-1148. doi:10.1111/j.1741-3737.2005.00206.x.

Barreto, M., \& Ellemers, N. (2005). The burden of benevolent sexism: How it contributes to the maintenance of gender inequalities. European Journal of Social Psychology, 35, 633-642. doi:10.1002/ejsp.270.

Baruh, L., \& Cemalc1lar, Z. (2015). Rubber necking effect of intimate information on twitter: When getting attention works against interpersonal attraction. Cyberpsychology, Behavior and Social Networking, 18(9), 506-513. doi:10.1089/cyber.2015.0099.

Becker, J. C., \& Wright, S. C. (2011). Yet another dark side of chivalry: Benevolent sexism undermines and hostile sexism motivates collective action for social change. Journal of Personality and Social Psychology, 101(1), 62-77. doi:10.1037/a0022615.

Caffaro, F., Mulas, C., \& Schmidt, S. (2016). The perception of honourrelated violence in female and male university students from Morocco, Cameroon, and Italy. Sex Roles. doi:10.1007/s11199015-0576-8. Advance online publication.

Ceylan, S. (2016). Social psychological predictors of violence against women in honor cultures (Unpbulished doctoral dissertation). Psychology Department, Middle East Technical University, Turkey.

Copur, Z., \& Koropeckyj-Cox, T. (2010). Universitystudents' perceptions of childless couples and parents in Ankara, Turkey. Journal of Family Issues, 31, 1481-1506. doi:10.1177/0192513X10361577.

Coşar, S., \& Onbașı, F. G. (2008). Women's movement in Turkey at a crossroads: From women'srights advocacy to feminism. South European Society and Politics, 13(3), 325-344. doi:10.1080/13608740802346585.

Dardenne, B., Dumont, M., \& Bollier, T. (2007). Insidious dangers ofbenevolent sexism: Consequences for women's performance. Journal of Personality and Social Psychology, 93, 764-779. doi:10.1037/0022-3514.93.5.764.

Eagly, A. H., Eaton, A., Rose, S. M., Riger, S., \& McHugh, M. C. (2012). Feminism and psychology: Analysis of a half-century of research on women and gender. American Psychologist, 67(3), 211-230. doi: $10.1037 / \mathrm{a} 0027260$.

Eckel, C. C., \& Grossman, P. J. (1996). The relative price of fairness: Gender differences in a punishment game. Journal of Economic Behavior \& Organization, 30(2), 143-158. doi:10.1016/S01672681(96)00854-2.

Flood, M. (2015). Work with men to end violence against women: A critical stocktake. Culture, Health \& Sexuality, 17, 159-176. doi:10.1080/13691058.2015.1070435.

Glick, P., \& Fiske, S. T. (1996). The ambivalent sexism inventory: Differentiating hostile andbenevolent sexism. Journal of Personality and Social Psychology, 70, 491-512. doi:10.1037/00223514.70.3.491.

Glick, P., Fiske, S. T., Mladinic, A., Saiz, J. L., Abrams, D., Masser, B., et al. (2000). Beyond prejudice as simple antipathy: Hostile and benevolent sexism across cultures. Journal of Personality and Social Psychology, 75, 763-775. doi:10.1037/0022-3514.79.5.763.

Glick, P., Sakallı-Uğurlu, N., Akbaș, G., Metin Orta, I., \& Ceylan, S. (2016). Why do women endorse honor beliefs? Ambivalent sexism and religiosity as predictors. Sex Roles. doi:10.1007/s11199-0150550-5. Advance online publication.

Guy, M. E., \& Newman, M. A. (2004). Women's jobs, men's jobs: Sex segregation and emotional labor. Public Administration Review, 64(3), 289-298. doi:10.1111/j.1540-6210.2004.00373.x.

Hamzah, S. R., Hamzah, A., Othman, J., \& Devi, S. (2016). Impact of Islamic values on the leadership style of Muslim women academics in Malaysia. Advances in Developing Human Resources, 18(2), 187-203. doi:10.1177/15234222316641402.

Husnu, S. (2016). The role of ambivalent sexism and religiosity in predicting attitudes toward childlessness in Muslim undergraduate students. Sex Roles. doi:10.1007/s11199-016-0639-5. Advance online publication.

İmamoğlu, O., \& Yasak, Y. (1993). Gazetelerde kadının ve erkeğin temsil ediliși [Representation of woman and man in newspapers]. Türk Psikoloji Dergisi [Journal of Turkish Psychology], 8(29), 23-30.

Jaggar, A. M., \& Rothenberg, P. S. (1993). Feminist frameworks: Alternative theoretical accounts of the relations between women and men. New York: McGraw-Hill, Inc. 
Jamil, F., \& Khalid, R. (2016). Factors contributing to depression during peri menopause: Findings of a Pakistani sample. Sex Roles. doi:10.1007/s11199-016-0690-2

Jost, J. T., \& Kay, A. C. (2005). Exposure to benevolent sexism and complementary gender stereotypes: Consequences for specific and diffuse forms of system justification. Journal of Personality and Social Psychology, 88, 498-509. doi:10.1037/0022-3514.88.3.498.

Kandiyoti, D. (1988). Bargaining with patriarchy. Gender and Society, 2, 274-290. doi:10.1177/089124388002003004.

Kandiyoti, D. (2011). Disentangling religion and politics: Whither gender equality? Institute of Development Studies Bulletin, 42(1), 10-14. doi:10.1111/j.1759-5436.2011.00195.x.

Klingorava, K., \& Hovlicek, T. (2015). Religion and gender inequality: The status of women in the societies of world religions. Moravian Geographical Reports, 23(2), 2-11. doi:10.1515/mgr-2015-0006.

Koropeckyj-Cox, T., \& Pendell, G. (2007). Attitudes about childlessness in the United States: Correlates of positive, neutral, and negative responses. Journal of Marriage and Family, 28, 1054-1082. doi:10.1177/0192513X07301940.

Küçük, S. (2013). Being a woman in Turkey and in the Middle East. Turkish Policy Quartely, 11(4), 23-43.

Kulwicki, A. D. (2002). The practice of honor crimes: A glimpse of domestic violence in the Arab world. Issues in Mental Health Nursing, 23, 77-87. doi:10.1080/01612840252825491.

Kumkale, G. T., \& Albarracín, D. (2004). The sleeper effect in persuasion: A meta-analytic review. Psychological Bulletin, 130, 143-172. doi:10.1037/0033-2909.130.1.143.

Leung, A. K., \& Cohen, D. (2011). Within- and between-culturevariation: Individual differences and the cultural logic of honor, face, and dignity cultures. Journal of Personality and Social Psychology, 100, 507-526. doi:10.1037/a0022151.

Lewin, E. (2005). Feminist anthropology: A reader. New Jersey: Wiley Blackwell Publishers.

Loewenthal, K. M., MacLeod, A. K., \& Cinnirella, M. (2002). Are women more religious than men? Gender differences in religious activity among different religious group in the UK. Personality and Individual Differences, 32, 133-139. doi:10.1016/S01918869(01)00011-3.

Metin-Camgoz, S., Tayfur-Ekmekci, O., Bayhan-Karapinar, P., \& Kumbul-Guler, B. (2016). Job insecurity and turnover intentions: Gender differences and the mediating role of work engagement. Sex Roles. doi:10.1007/s11199-016-0595-0. Advance online publication.

Moghadam, V. (1998). Women, work, and economic reform in the Middle East and North Africa. Boulder: Lynne Rienner Publishers.

Moya, M., Glick, P., Exposito, F., De Lemus, S., \& Hart, J. (2007). It's for your own good: Benevolent sexism and women's tolerance of paternalistic discrimination by intimate partners. Personality and Social Psychology Bulletin, 33, 1421-1434. doi: $10.1177 / 0146167207304790$.

Naiper, J. L., Thorisdottir, H., \& Jost, J. T. (2010). The joy of sexism? A multinational investigation of hostile and benevolent justifications for gender inequality and their relations to subjective well-being. Sex Roles, 62, 405-419. doi:10.1007/s11199-009-9712-7.

Naviar Sen, C., Baruh, L., \& Kumkale, T. (2016). Beyond a paycheck: The influence of workforce participation on women's cancer screeing in Turkey. Sex Roles. doi:10.1007/s11199-016-0611-4. Advance online publication.

Netchaeva, E., Kouchaki, M., \& Sheppard, L. D. (2015). A man's (precarious) place: Men'sexperienced threat and self-assertive reactions to female superiors. Personality and Social Psychology Bulletin, 41, 1247-1259. doi:10.1177/0146167215593491.

Peristiany, J. G. (1965). Honour and shame: The values of Mediterranean society. London: Weidenfeld and Nicolson.

Richardson, L., \& Taylor, V. (1983). Feminist frontiers: Rethinking sex, gender, \& society. Reading: Addison-Wesley.
Rosenblatt, Z., Talmud, I., \& Ruvio, A. (1999). A gender-based framework of the experience of job insecurity and its effects on work attitudes. European Journal of Work and Organizational Psychology, 8(2), 197-217. doi:10.1080/135943299398320.

Sakall, N. (2001). Beliefs about wife beating among Turkish college students: The effects of patriarchy, sexism and sex difference. Sex Roles, 44(9/10), 599-611. doi:10.1023/A:1012295109711.

Sakallı-Uğurlu, N., \& Akbaș, G. (2013). Namus kültürlerinde "namus" ve "namus adınakadına șiddet": Sosyal psikolojik açıklamalar ["Honor" and "violence against women in the name of honor" in honor cultures]. Türk Psikoloji Yazılarl [Turkish Psychological Articles], 16(32), 76-91.

Sakall1-Uğurlu, N., \& Glick, P. (2003). Ambivalent sexism and attitudes toward women who engage in premarital sex in Turkey. The Journal of Sex Research, 40(3), 296-302. doi:10.1080/00224490309552194.

Sakallı-Uğurlu, N., \& Türkoğlu, B. (2016). Türkiye'deki cinsiyet kalipyargılart: Kadın kimdir? Erkek kimdir? [Gender stereotypes in Turkey: Who is woman? Who is man?]. Unpublished manuscript.

Sakallı-Uğurlu, N., Yalçın, S. Z., \& Glick, P. (2007). Ambivalent sexism, belief in a just world, and empathy as predictors of Turkish students' attitudes toward rape victims. Sex Roles, 57(11/12), 889-895. doi:10.1007/s11199-007-9313-2.

Sakallı-Uğurlu, N., Salman, S., \& Turgut, S. (2010). Predictors of Turkish women's and men's attitudes toward sexual harassment: Ambivalent sexism, and ambivalence toward men. Sex Roles, 63, 871-881. doi:10.1007/s11199-010-9847-6.

Sechzer, J. A. (2004). "Islam and women: Where tradition meets modernity": History and interpretation of Islamic women's status. Sex Roles, 51(5), 263-272. doi:10.1023/B:SERS.0000046610.16101.e0.

Sever, A., \& Yurdakul, G. (2001). Culture of honor, culture of change: A feminist analysis of honor killings in Turkey. Violence Against Women, 7, 964-998. doi:10.1177/10778010122182866.

Sheridan, L. P., \& North, A. C. (2004). Representations of Islam and Muslim in psychological publications. The International Journal for the Psychology of Religion, 14(3), 149-159. doi:10.1207/s15327582ijpr1403_1.

Sherif, M. (1935). A study of some social factors in perception. Archives of Psychology, 27, 187-188.

Skevington, S. M. (2010). Qualities of life, educational level and human development: An international investigation of health. Social Psychiatry Epidemiol, 45, 999-1009. doi:10.1007/s00127-0090138-x.

Staufenbiel, T., \& König, C. J. (2010). A model for the effects of job insecurity on performance, turnover intention, and absenteeism. Journal of Occupational and OrganizationalPsychology, 83(1), 101-117. doi:10.1348/096317908X401912.

Sunar, D. (2002). Change and continuity in theTurkish middle class family. In E. Özdalga \& R. Liljestrom (Eds.), Autonomy and dependence in family: Turkey and Sweden in criticalperspective (pp. 217-237). Istanbul: Swedish Research Institute.

Swim, J. K., Aikin, K. J., Hall, W. S., \& Hunter, B. A. (1995). Sexism and racism: Old-fashionedand modern prejudices. Journal of Personality and Social Psychology, 68, 199-214. doi:10.1037/0022-3514.68.2.199.

Swim, J. K., Mallett, R., Russo-Devosa, Y., \& Stangor, C. (2005). Judgments of sexism: A comparison of the subtlety of sexism measures and sources of variability in judgments of sexism. Psychology of Women Quarterly, 29, 406-411. doi:10.1111/ j.1471-6402.2005.00240.x.

Taşdemir, N., \& Sakalli-Uğurlu, N. (2010). The relationship between religiosity, and ambivalent sexism among Turkish students. Sex Roles, 62(7-8), 420-426. doi:10.1007/s11199-009-9693-6.

Vandello, J. A., \& Bosson, J. K. (2013). Hard to won and easily lost: A review and synthesis of theory and research on precarious manhood. 
Psychology of Men \& Masculinity, 14(2), 101-113. doi:10.1037/ a0029826.

Vandello, J. A., Cohen, D., Grandon, R., \& Franiuk, R. (2009). Stand by your man: Indirect prescriptions for honorable violence and feminine loyalty in Canada, Chile, and the United States.
Journal of Cross-Cultural Psychology, 40, 81-104. doi:10.1177/ 0022022108326194.

World Economic Forum. (2016, September). Global Gender Gap Report: 2015. Retrieved from https://www.weforum.org/reports/globalgender-gap-report-2015. 